1 Fundação Oswaldo Cruz (Fiocruz), Escola Politécnica de Saúde Joaquim Venâncio (EPSJV) - Rio de Janeiro (RJ), Brasil. julianavalentim@fiocruz.br

2 Pontifícia Universidade Católica do Rio de Janeiro (PUC-Rio), Departamento de Geografia e Meio Ambiente, Laboratório de Ecologia e Biogeografia Rio de Janeiro (RJ), Brasil. marialucienelima@gmail. com

${ }^{3}$ Fundação Oswaldo Cruz (Fiocruz), Escola Politécnica de Saúde Joaquim Venâncio (EPSJV) - Rio de Janeiro (RJ), Brasil. raiane.fontes.oliveira@ gmail.com

4 Fundação Oswaldo Cruz (Fiocruz), Escola Politécnica de Saúde Joaquim Venâncio (EPSJV) - Rio de Janeiro (RJ), Brasil. mmonken@fiocruz.br

5 Universidade Federal Fluminense (UFF), Instituto de Saúde da Comunidade (ISC) - Niterói (RJ), Brasil. mlfpenna@id.uff.br

\section{Estudo espacial de riscos à leptospirose no município do Rio de Janeiro (RJ)}

\author{
Spatial study of risks to leptospirosis in the municipality of Rio de \\ Janeiro $(R J)$
}

Juliana Valentim Chaiblich', Maria Luciene da Silva Lima², Raiane Fontes de Oliveira ${ }^{\mathbf{3}}$, Maurício Monken ${ }^{4}$, Maria Lucia Fernandes Penna ${ }^{5}$

RESUMO A leptospirose é relevante para saúde pública pela sua gravidade e modo de disseminação, cuja ocorrência é maior em local com vulnerabilidade socioambiental. No município do Rio de Janeiro, os casos estariam relacionados com sua estrutura social e espacial. Analisou-se a espacialidade da leptospirose nesse município, de 2000 a 2010, por meio de mapas e observações de campo. Resultados sugeriram que os bairros de Barra de Guaratiba, Pedra de Guaratiba e Grumari foram de alto risco - locais com estruturas sanitárias precárias e constantes alagamentos. Ações da Vigilância em Saúde são de grande importância na identificação e intervenção em locais de situações risco à saúde.

PALAVRAS-CHAVE Leptospirose. Vulnerabilidade social. Análise espacial. Risco.

ABSTRACT Leptospirosis is relevant to public health because of its severity and mode of dissemination, being its occurrence greater in places with socio-environmental vulnerability. In the municipality of Rio de Janeiro, the cases would be related to their social and spatial structure. The spatiality of leptospirosis in such city, from 2000 to 2010, was analyzed through maps and field observations. Results suggested that Barra de Guaratiba, Pedra de Guaratiba and Grumari are neighborhoods of high risk - places with poor sanitary structures and constant flooding. Health Surveillance actions are of great importance in identifying and intervening in places of health risk situations.

KEYWORDS Leptospirosis. Social vulnerability. Spatial analysis. Risk. 


\section{Introdução}

A leptospirose é uma doença infecciosa originada por uma bactéria, com quadro clínico que pode variar desde infecções assintomáticas até formas graves, podendo levar a óbito. A sua letalidade é alta, podendo chegar a $40 \%$ dos casos. Quando a forma da doença é branda, comumente é diagnosticada como síndrome gripal, virose, influenza ou dengue, pela semelhança dos sintomas. Trata-se, porém, de uma zoonose de grande importância social e econômica: por seus elevados índices de incidência, a letalidade nos casos mais graves e o alto custo hospitalar (BRASIL, 2009).

O agente etiológico é a bactéria aeróbica do gênero Leptospira. Mais de 200 sorovares (sorotipos) já foram identificados. O sorovar pode determinar as diversas formas de apresentação clínica no homem. No Brasil, os sorovares Icterohaemorrhagiae e Copenhageni estão relacionados com os casos mais graves (BRASIL, 2014).

Os principais reservatórios são os roedores das espécies Rattus norvegicus (ratazana ou rato de esgoto), Rattus rattus (rato de telhado ou rato preto) e Mus musculus (camundongo ou catita). Esses animais não desenvolvem a doença quando infectados e albergam a leptospira nos rins, eliminando-a viva no meio ambiente. O Rattus norvegicus é o principal portador do sorovar Icterohaemorraghiae, um dos mais patogênicos para o homem (BRASIL, 2014).

A Leptospira possui a capacidade de viver em variados ambientes, por tempo bem prolongado. O contágio ocorre quando o agente infeccioso entra em contato direto com mucosa ou onde haja lesões na pele, seja por meio de água, solo e alimentos contaminados pela urina de animais infectados (GONÇALVESDE-ALBUQUERQUE, 2012).

Anteriormente, a leptospirose era vista como uma doença que ocorria eventualmente em áreas rurais. Na atualidade, é uma doença considerada de áreas urbanas, principalmente nas localidades que houve crescimento desordenado e com precariedade nos serviços de saneamentos, o que facilita a proliferação de ratos nessas áreas. (ALEIXO; SANT'ANNA NETO, 2010).

Nos países tropicais, ocorrem surtos epidêmicos da leptospirose, principalmente em locais sujeitos a inundações ocasionadas pela chuva. Dessa forma, ela se torna uma doença preocupante para saúde pública pela gravidade e o modo de disseminação em áreas urbanas (GONÇALVES-DE-ALBUQUERQUE, 2012). No Brasil, é uma doença endêmica, porém torna-se epidêmica pela ocorrência de inundações nos períodos chuvosos; sobretudo nos grandes conglomerados humanos de baixa renda, com alta infestação de roedores e condições improprias de saneamento (BRASIL, 2009).

A média anual de casos confirmados nos últimos 10 anos é de 3.600 casos no Brasil, em sua maioria nas regiões Sudeste e Sul. Nesse mesmo período, foram registrados 375 óbitos em média, a cada ano (BRASIL, 2014). O Rio de Janeiro, entre 1985 e 2005, esteve entre os estados com maior incidência de leptospirose.

No estado do Rio de Janeiro, foram identificados casos esporádicos de leptospirose antes da década de 1960. Contudo, a partir dessa década, surgiram surtos epidêmicos após inundações causadas por chuvas fortes. No ano de 1988, em seus primeiros meses, diversas cidades do estado enfrentaram chuvas fortes que ocasionaram inundações em vários municípios, como Duque de Caxias, Nova Iguaçu, Nilópolis, Belfort Roxo, São João de Meriti e regiões da Capital, circunvizinhas à Baixada Fluminense. Ocorreram, nesse mesmo ano, 1.117 casos de leptospirose. A partir de então, observou-se que casos de leptospirose surgiam em regiões atingidas por inundações (GONÇALVES ET AL., 1992).

No município do Rio de Janeiro, é possível observar dois períodos em que houve picos na taxa de leptospirose no município, nos anos de 1988 e 1996, que foram considerados epidêmicos. A transmissão de leptospirose nesse município estaria relacionada com a estrutura social e espacial da cidade - maior 
vulnerabilidade da população residindo em áreas desordenadas, com problemas de infraestrutura urbana e áreas sujeitas à inundação (CARRIJO, 2008).

Entre 2000 e 2010, no município do Rio de Janeiro, os números de morbidade por leptospirose obtiveram uma constância, com a média de 70 casos por ano - esse período não possui nenhum ano considerado epidêmico. Já a média de casos de mortalidade foi 15 por ano, e a média do coeficiente de letalidade foi de 22,5 por 100 indivíduos, no mesmo período.

$\mathrm{O}$ objetivo deste artigo foi analisar a distribuição espacial da taxa de incidência da leptospirose, no período de 2000 a 2010, no Município do Rio de Janeiro, identificando os bairros do município com possíveis riscos na ocorrência da doença. Destacam-se áreas de vulnerabilidades socioambientais à doença, os locais onde a população vive em condições geográficas propícias a inundações, com precariedades nos serviços básicos de saneamento e de grandes aglomerações humanas.

\section{Processos metodológicos}

\section{Área de estudo}

O município do Rio de Janeiro é a capital do estado do Rio de Janeiro, localizada na Região Sudeste, Brasil. Segundo os dados censitários de 2010, a população do município era de 6.320.446, com a área territorial $\left(\mathrm{km}^{2}\right)$ de 1.197,463. A densidade demográfica (hab./ $\mathrm{km}^{2}$ ) era de 5.265,82. Oficialmente é um município $100 \%$ urbano, apesar da existência de localidades com atividades agrícolas. A cidade é composta por 161 bairros, 33 Regiões Administrativa e 5 Áreas de Planejamento. O município é o núcleo da Região Metropolitana do Rio de Janeiro.

A cidade do Rio de Janeiro apresenta uma paisagem incomum no contexto urbano, que se expandiu pela planície - locais da Baixada de Santa Cruz, de Jacarepaguá e Fluminense. O seu processo urbano cresceu em direção aos maciços montanhosos da Pedra Branca, de Gericinó-Mendanha e, principalmente, o Maciço da Tijuca (GUeRRA, 2011).

O clima predominante no Rio de Janeiro é tropical, com temperatura predominantemente quente. Embora frentes frias atuem frequentemente durante o inverno, é no verão que causam maior impacto com as chuvas intensas sobre a região (BRANDÃo, 1992). A substituição das florestas por feições urbanas está ocasionando um transbordamento de águas pluviais, provocando inundações. As enchentes não se dão somente pelas fortes chuvas, acontecem também pela falta de capacidade de escoamento das águas pluviais e pela incapacidade de infiltração da água no solo (GALVÃo, 1992).

\section{Variáveis de interesse e fontes de dados}

A partir do levantamento dos dados secundários, foram definidas sete variáveis de interesse para processamento de mapas estruturais. Foi feita aquisição destes para construção de banco de dados, os quais foram manipulados em ambiente georreferenciado. A manipulação dos dados consistiu na padronização das escalas do mapeamento e sistema de referência e coordenadas. Todos os mapas foram gerados por meio do ArcGis 10.3. Utilizaram-se dados de formato tabular e geoespaciais ESRI Shapefile.

Abaixo, os dados de formato shapefile e suas fontes:

Áreas de Favela - Instituto Pereira Passos (IPP), 2010.

Uso e ocupação do solo - Secretaria Municipal de Meio Ambiente (SMAC), 2010.

Geomorfologia - Instituto Estadual do Ambiente (Inea), 2010. 
Os dados em formatos de tabelas foram organizados na extensão xls, oriundos das informações do Censo (Instituto Brasileiro de Geografia e Estatística - IBGE/IPP) e do Sistema de Informação de Agravos de Notificação (Sinan). Esse banco foi separado por bairro (unidade territorial de análise). Seguem as variáveis e as suas fontes:

Taxa de Incidência de leptospirose no município do Rio de Janeiro - Sinan, 2000 a 2010.

Porcentagem de Domicílios Particulares Permanentes com até um salário mínimo de rendimento mensal per capita - Censo Demográfico (IBGE/IPP), 2010.

Porcentagem de Domicílios Particulares Permanentes com abastecimento de água da rede geral - Censo Demográfico (IPP/ IBGE), 2010.

Porcentagem de Domicílios Particulares Permanentes com esgotamento sanitário Censo Demográfico (IPP/IBGE), 2010.

Porcentagem de Domicílios particulares permanentes com coleta de lixo por meio dos serviços de limpeza pública ou privada - Censo Demográfico (IPP/IBGE), 2010.

\section{Análise espacial}

A partir dos dados de casos de leptospirose e do número de população, separados por bairros do município do Rio de Janeiro, foram calculadas as taxas de incidência dos anos de 2000 a 2010 (período do estudo desta pesquisa). A partir desse indicador, foram processados dois tipos de modelagens estatísticas, estimador Bayesiano empírico local e densidade de Kernel. Pretende-se com estas técnicas localizar os bairros do município do Rio de Janeiro que tiveram as taxas de incidência mais elevadas, subsidiando a análise das áreas de maior risco da doença.
A análise de dispersão espacial do risco de um evento é realizada, no caso de uma doença, por meio de mapas de taxas de incidência, nos quais as áreas são destacadas de acordo com os valores dessa taxa. Essa é uma taxa bruta, sendo um estimador mais simples para o risco de ocorrência de um acontecimento, em que pode ocorrer uma instabilidade ao expressar o risco de um determinado evento, principalmente, quando a população da área sob risco é pequena e o evento incidir esporadicamente. Nesse sentido, as flutuações aleatórias casuais, como a ocorrência de um ou dois casos do evento (a mais ou a menos) em uma localidade específica, determinam alterações substanciais das taxas brutas se a sua população for pequena. Outra situação de correção é quando não há ocorrências de casos do determinado evento em alguma localidade (mesmo quando nos territórios vizinhos a ocorrência é alta), a taxa bruta estima o risco de ocorrência como zero, o que pode tratar-se de um fato é ilusório (SANTOS ET AL., 2005).

Nessa perspectiva, a fim de corrigir as taxas brutas de incidência, utilizou-se o estimador Bayesiano empírico local. O estimador de Bayes local apresenta resultados espaciais mais estáveis, pois leva em consideração no cálculo não só a informação daquela determinada área, mas também os dados dos vizinhos geográficos, convergindo em direção a uma média local (SANTOS ET AL., 2005).

Nesse caso, segundo Souza et al. (2007), é suposto que a taxa real $\theta i$, expressa a força de ocorrência do evento na área i, seja uma variável aleatória com média $\mu$ i e variância $\theta i$. O estimador dessa taxa é uma combinação linear entre a taxa observada (eventos/população) na área $i$ e um valor médio $\mu i$, ponderados por um fator wi. pelo seguinte cálculo: $\theta i=\mathrm{w} i \mathrm{t} i+(1-\mathrm{w} i) \mu i$.

No intuito de complementar as análises de risco da leptospirose (2000 a 2010), foi utilizada outra técnica de análise estatística espacial, a densidade de Kernel.

A densidade de Kernel é uma técnica 
estatística, em que a distribuição de eventos é transformada em uma superfície contínua. Trata-se de um interpolador que permite a estimativa da densidade do evento em toda a área. Assim, podem-se identificar as 'áreas quentes' onde houve maiores ocorrências do evento. Nesse sentido, tem como finalidade avaliar a ocorrência de eventos no espaço. É possível dizer que esse estimador consiste em aferir em uma determinada área, o evento esperado (SANTOS ET AL., 2012).

Sendo Kernel uma palavra inglesa que significa 'centro' ou 'núcleo', e seguindo o seu significado, com o seu mapa, é possível observar o valor central, em que há uma intensidade pontual maior de um determinado fenômeno na área de estudo, e ponderar a distância em relação a esse valor central.

A densidade de Kernel se ajusta por uma função bidimensional sobre os eventos analisados, compondo uma superfície cujo valor é proporcional à densidade de amostras por unidade de área. A função Kernel executa uma contagem de todos os pontos dentro de um raio de influência, considerando a distância entre elas (BERGAMASCHI, 2010).

\section{Análise de campo}

Foram realizadas observações de campo das localidades de maior risco à leptospirose. Os resultados sobre a distribuição espacial da leptospirose, no período de 2000 a 2010 no município do Rio de Janeiro, sugeriram alguns bairros de maior risco à essa doença, sendo classificados como áreas de risco com taxa de incidência muito alta.

As atividades realizadas em campo se deram por visitas aos bairros de maior risco (apontados nos resultados desta pesquisa os bairros Barra de Guaratiba, Pedra de Guaratiba e Grumari), observando os aspectos socioambientais de cada local. Além disso, foram captadas imagens de alguns Pontos de Observação (PO).

\section{Resultados}

A figura 1 mostra a taxa de incidência de leptospirose (considerando estimativa bayesiana) e densidade de Kernel da taxa de incidência, no período de 2000 a 2010, por bairros do município do Rio de Janeiro.

Observou-se que os bairros de Barra de Guaratiba, Pedra de Guaratiba e Grumari, localizados na zona oeste da cidade, foram os que obtiveram as taxas maiores de incidência de leptospirose (TI acima 100 casos por 100.000 habitantes). O mapeamento de densidade de Kernel mostra localidades no município de possíveis riscos na transmissão da leptospirose. As áreas de maior intensidade no mapa são locais que obtiveram as taxas maiores: quanto maior intensidade, maior o risco de incidência.

$\mathrm{Na}$ análise espacial do Kernel, levaram-se em consideração os bairros próximos que tiveram taxas de incidência significativas. Nos bairros pertencentes da zona norte e central, também se observou uma intensidade no mapeamento de Kernel. Nessas áreas ficaram em evidência no mapeamento de Kernel vários bairros próximos que obtiveram taxas moderadas e altas de incidência da doença. 
Figura 1. Mapa da taxa de incidência de leptospirose e densidade de Kernel, no período de 2000 a 200 no município do Rio de Janeiro

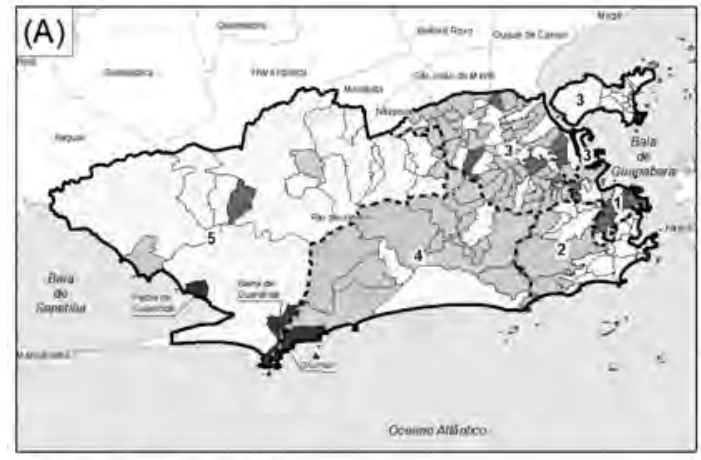

Convençôes Cartográficas \$.3 Lagoas

Limites municipais

5. Limite dos Bairros

$\therefore$ Áreas de Planejamento

Legenda

C Área de Estudo

(A) Taxa de Incidência de leptospirose por 100.000 hab - (Estimador Bayesiano)

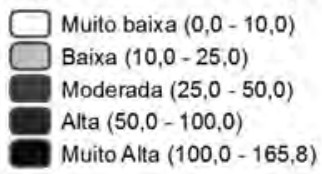

(B)Taxa de Incidéncia da lepstospirse (Estimador Bayesiano) Niveis Kernel

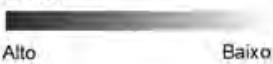

A figura 2 refere-se ao mapa de geomorfologia do município do Rio de Janeiro, que mostra as áreas de maiores altitudes, como os maciços, colinas e áreas de planícies fluviais e fluviomarinhas. O elemento relevo é

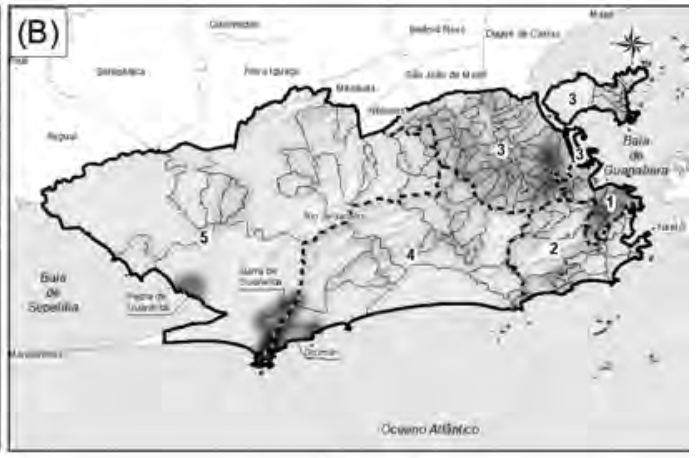

Mapa de Situação

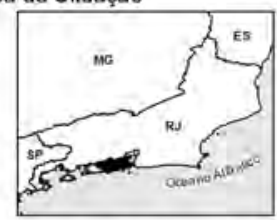

Referências cartográficas

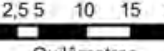

Quilômetros

Escala: 1:1.000.000

SISTEMA DE COORDENADAS GEOGRAFICAS Datum Honizontal: SIRGAS 2000 uma condicionante importante na avaliação dos processos de ocupação, evidenciando um processo histórico de adensamento urbano nas baixadas. 
Figura 2. Mapa da geomorfologia do município do Rio de Janeiro

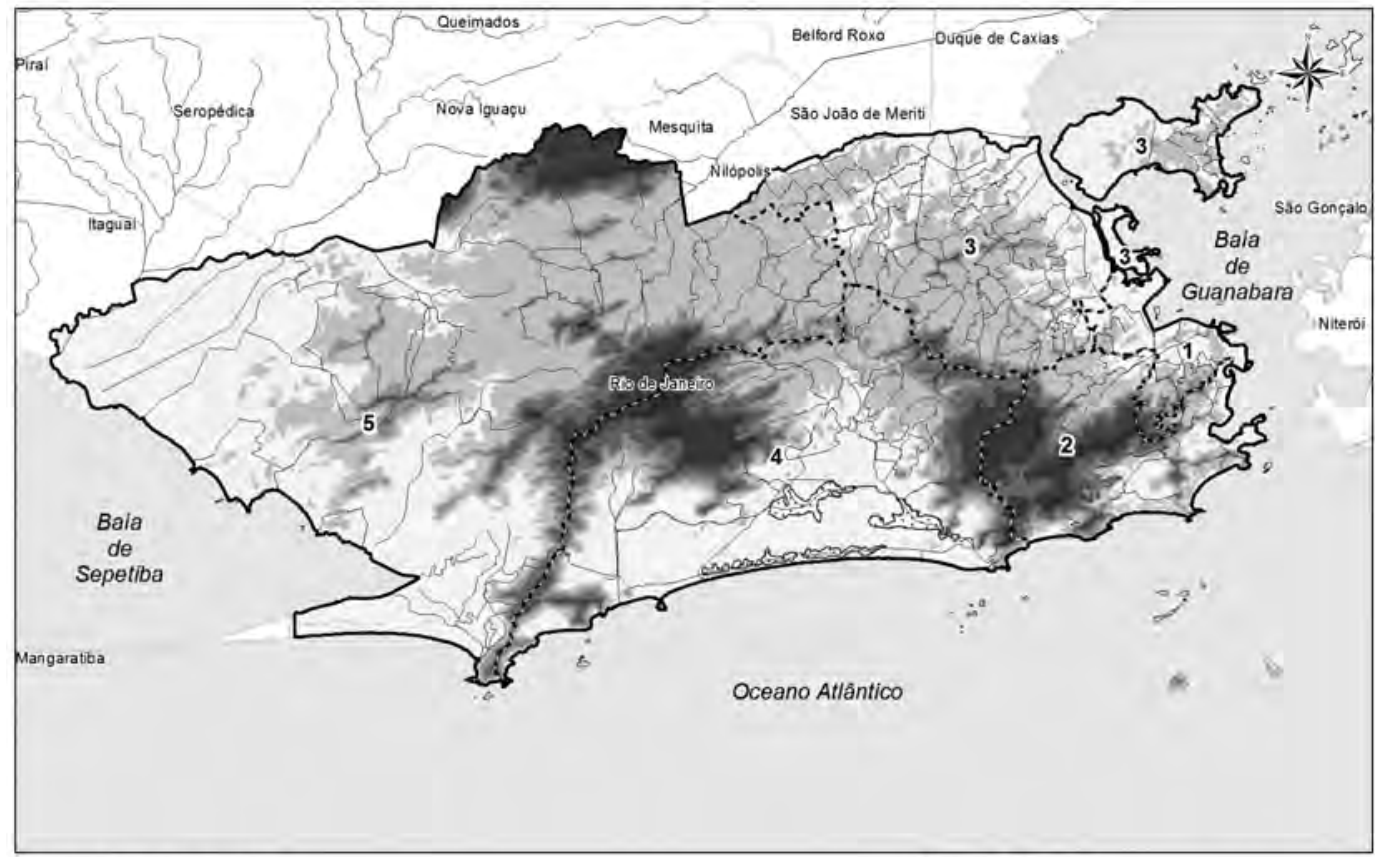

Convenções Cartográficas

Curso d'água

\$3 Lagoas

Limites municipais

5 Limite dos Bairros

Áreas de Planejamento

Legenda

Z Área de Estudo

Niveis de altimetria $(m)$

3 Planicies fluviais e fluviomarinhas $(0-20)$

3 Colinas $(20-100)$

3 Morros (100 - 200)

Serras isoloadas e locais $(200-400)$

Serras Escarpadas $(400-1.011)$
Mapa de Situaçăo

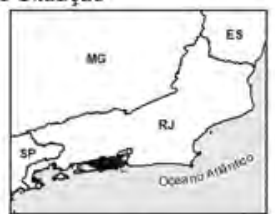

Referências cartográficas

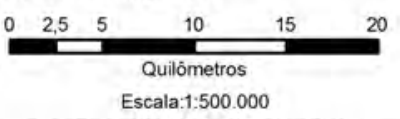

SISTEMA DE COORDENADAS GEOGRAFICAS Datum Honizontal: SIRGAS 2000
A figura 3 retrata sobre mapeamento de uso e ocupação do solo no município do Rio de Janeiro, em que é possível observar as áreas de influência antrópicas (agrícolas e não agrícolas), ou seja, localidades de ocupação humana, além de áreas de florestas, formações pioneiras e campestres. 
Figura 3. Mapa do uso e ocupação do solo no município do Rio de Janeiro

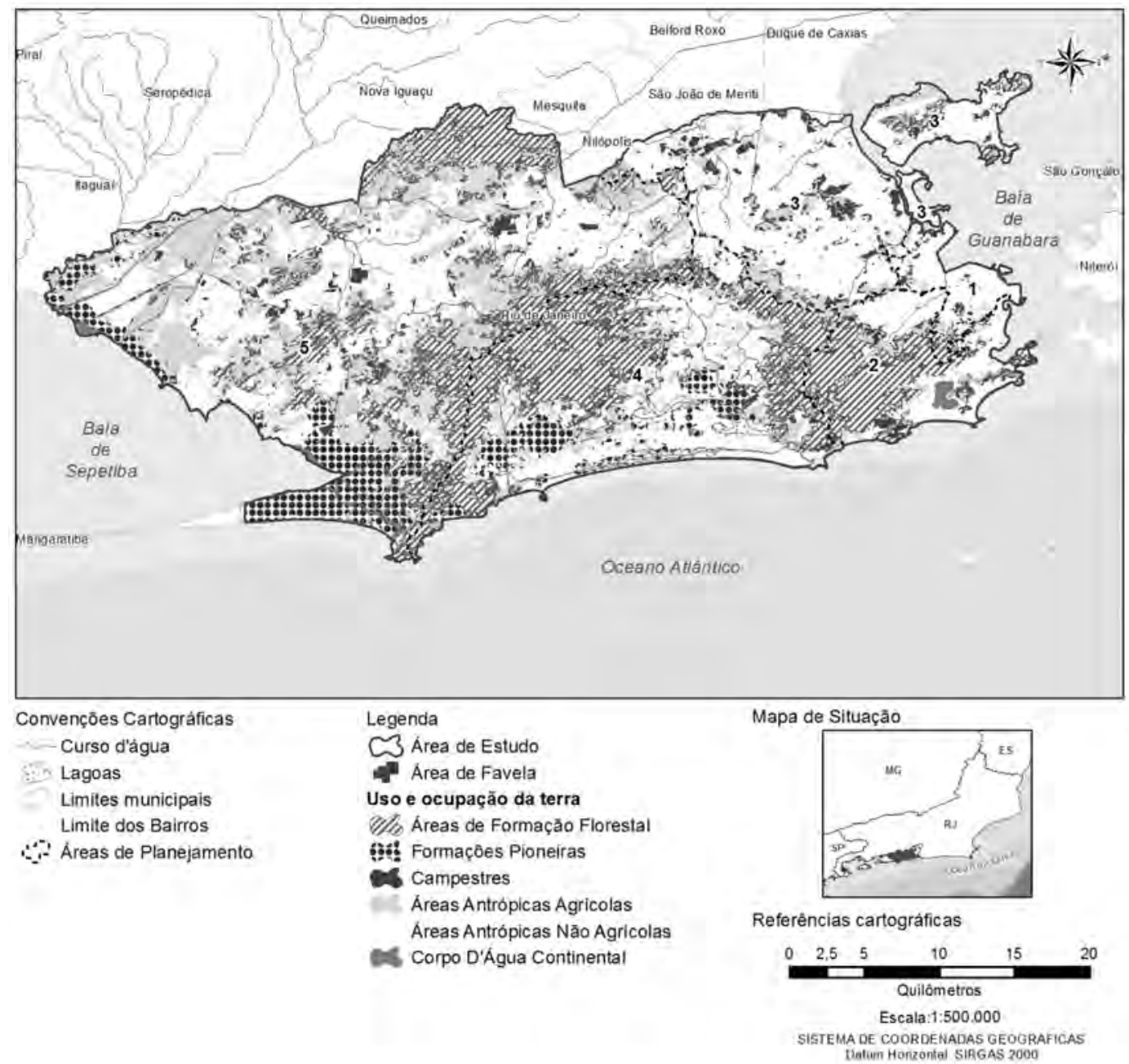

Observa-se que as áreas antrópicas não agrícolas estão localizadas nas regiões de menor altitude. Percebe-se ainda na figura 3 que as áreas de favelas estão distribuídas em todo território do município, em que se destacam os bairros da zona norte e do centro da cidade, por possuírem grandes densidades de áreas de favelas.

Os bairros de Pedra de Guaratiba, Barra de Guaratiba e Grumari são áreas do litoral do município e possuem uma região ampla de vegetação, ecossistemas e concentração de redes fluviais, com características antrópicas agrícolas. Pedra de Guaratiba e Barra de Guaratiba possuem extensa área de mangue, e parte da área é ocupada desordenadamente por residências. Barra de Guaratiba e Grumari estão localizados na ponta do Maciço da Pedra Branca com grande parte da extensão territorial acima de 100 metros. São as áreas baixas próximas à encosta que possuem as habitações populacionais que são propícias às inundações em épocas de chuvas. As inundações são comumente ocorridas nesses bairros, pois são locais de áreas alagadiças (mangue) e que têm grandes concentrações de redes fluviais.

A figura 4 refere-se às características sanitárias e renda per capita da cidade. 
Figura 4. Mapa de serviços de saneamento e renda
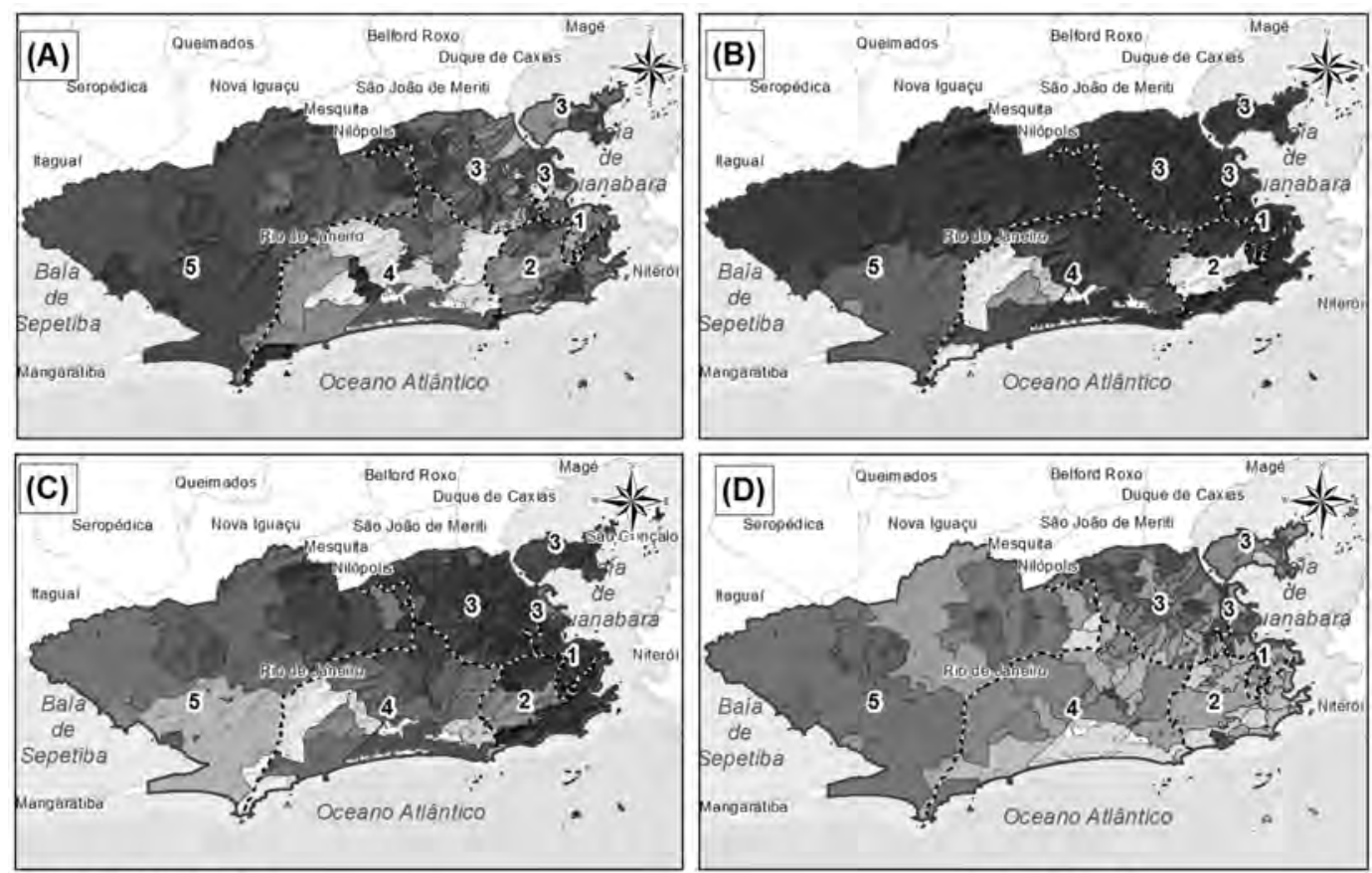

Convençōes Cartográficas

Lagoas Limite dos Bairros

Limites municipais Areas de Planejamento

Legenda

3 Área de Estudo

Área de Favela

(A) Domicilios Particulares Permanentes com Coleta de lixo - público e privado (\%) Niveis

Muito alto: $100 \quad$ Muito baixo: 18

(B) Domicilios Particulares Permanentes com abastecimento de água (\%)

Niveis

Muito alto: $100 \quad$ Muito baixo: 9

Mapa de Situação

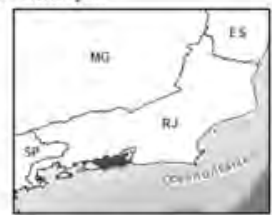

Referências cartogrăficas

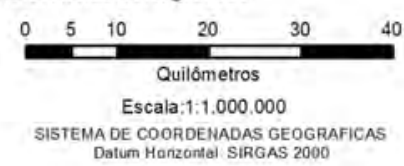

(C) Domicilios Particulares Permanentes com Esgotamento Sanitàrio (\%)

Niveis

Muito alto: $99 \quad$ Muito baixo: 0

(D) Domicilios Particulares Permanente de atè 1 salàrio minimo - rendimento mensal per capita (\%)

Niveis

Alto Baixo

Em relação aos serviços de abastecimento de água, de esgotamento sanitário e de coleta de lixo, há fragilidades nos bairros da zona oeste. A falta de coleta de lixo se acentua, principalmente, na região de Jacarepaguá. Nos bairros da zona norte e centro, observam-se também uma debilidade na coleta de lixo. Muitos bairros da cidade possuem áreas geográficas com maior dificuldade para realização da coleta de lixo, levando ao poder público criar estratégias de serviços de coletas por caçambas de lixo, principalmente em áreas de favelas.

Os bairros da zona norte e centro, apesar dos dados apontarem uma oferta de serviços como abastecimento de água e coleta 
de esgoto, são áreas que possuem grande número de habitantes vivendo em locais de favela com precariedades habitacionais e dos serviços de infraestrutura sanitária.

Nota-se que os bairros de Barra de Guaratiba, Pedra de Guaratiba e Grumari possuem fragilidades nos serviços sanitários oferecidos. Em Barra de Guaratiba, todos os serviços (água, esgoto e lixo) são precários. Em Pedra de Guaratiba e Grumari, a infraestrutura mais precária é em relação ao esgotamento sanitário e ao abastecimento de água.
Em relação à população com renda baixa, nos bairros de Barra de Guaratiba e Pedra de Guaratiba, quase $50 \%$ das pessoas vivem em domicílios com renda de até um salário mínimo, e em Grumari, esse percentual é mais alto, 100\% (IBGE, 2010).

Foram realizados Pontos de Observação, figura 5, referentes aos bairros de Barra de Guaratiba, Pedra de Guaratiba e Grumari, onde foram feitas descrições de possíveis situações de vulnerabilidades socioambientais.

Figura 5. Pontos de Observação (PO) dos bairros do município do Rio de Janeiro que obtiveram maiores taxas de incidência de leptospirose - Barra de Guaratiba (PO1 e PO2), Pedra de Guaratiba (PO3 e PO4) e Grumari (PO5 e PO6)
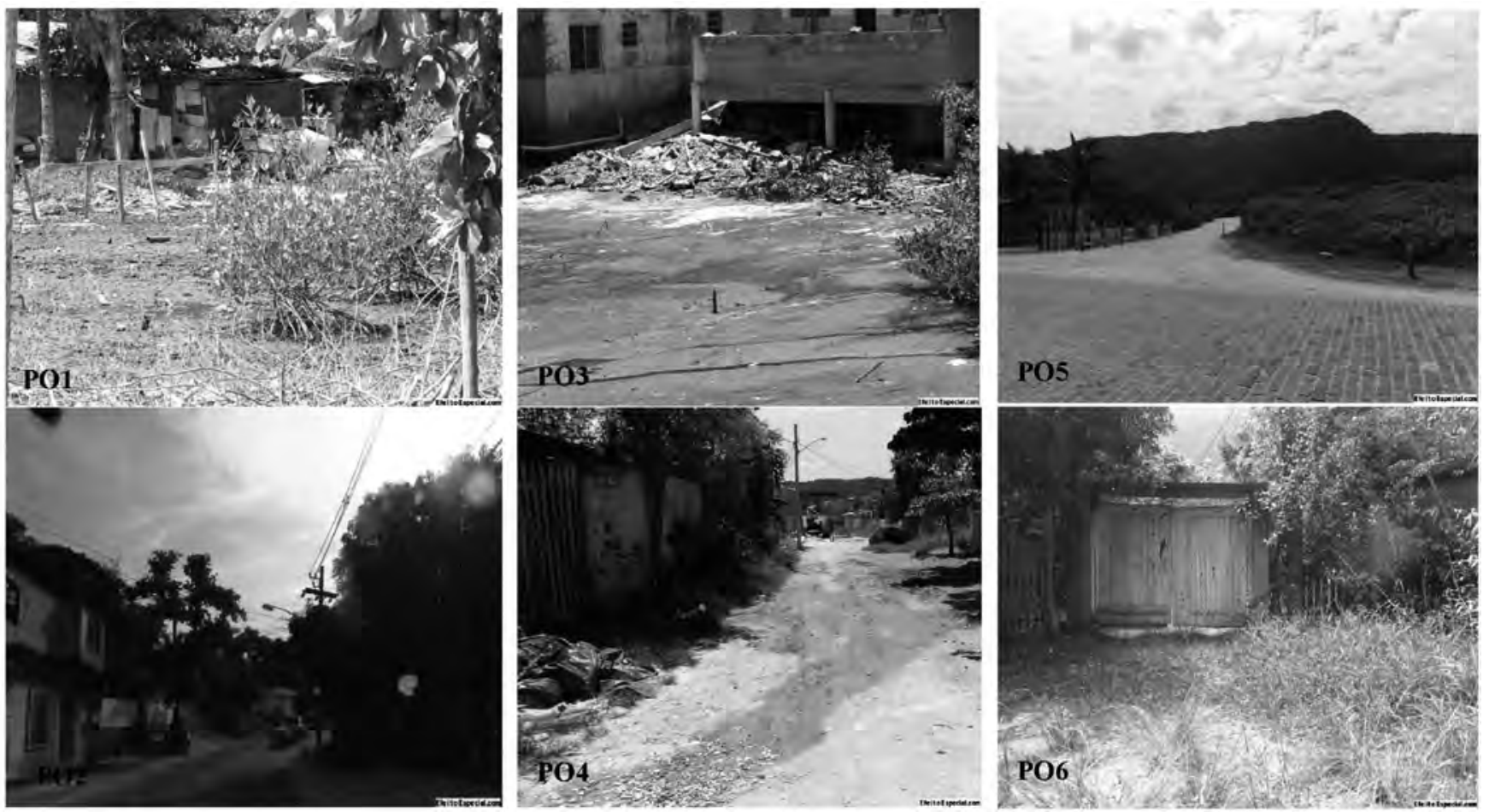

Fonte: Fotografias realizadas em outubro de 2015 e janeiro de 2016 - produção própria dos autores 
Os PO 1 e 2 foram realizados na Estrada Roberto Burle Marx, o principal acesso ao bairro de Barra de Guaratiba. Está visível a invasão dos manguezais pelas habitações, com descarte irregular de lixo, entulho e esgoto doméstico in natura, provavelmente, pela ausência da prestação do serviço de coleta regular, por parte do poder público municipal.

Os PO 3 e 4 são referentes ao bairro de Pedra de Guaratiba. O PO 3 localiza-se na área do mangue da baia de Sepetiba, e também apresenta características de degradação pelo lixo e o esgoto sanitário das casas e do comércio existentes na localidade. O PO 4 trata-se de uma das ruas perpendiculares à Estrada da Matriz, principal acesso ao bairro da Pedra de Guaratiba. As poças de água em via pública são remanescentes das chuvas ocorridas dias antes, nosso que leva a acreditar na inexistência de infraestrutura básica de coleta das águas pluviais. Também se constatou que são ruas com estruturas precárias, sem pavimentação e, aparentemente, sem rede de coleta e tratamento de esgoto sanitário.

As imagens dos PO 5 e 6 trata-se do bairro de Grumari, cuja localidade refere-se a uma região turística de belas praias e natureza exuberante. $\mathrm{O}$ bairro atrai intenso fluxo de pessoas, consequentemente, gerando elevada produção de lixo, devido à exploração comercial em sua orla, onde há coleta regular do lixo. Observou-se grande quantidade de lixo abandonado na faixa de areia da praia. Apesar de ainda estar preservada da excessiva especulação imobiliária no seu litoral, foram encontradas residências nas áreas internas e planas, em um total de 44 domicílios na localidade (IBGE, 2010). Pela presença de coletores de lixo em seus logradouros internos, acredita-se na existência da prestação de serviço de coleta regular, ainda que tenha sido observada a presença de lixo na vegetação às margens das ruas. Apesar de não se ter observado a presença de valas negras ou córregos poluídos por esgoto, o mal cheiro sugere que inexiste rede de coleta do esgoto sanitário, e há provável utilização do sistema sumidouros. Houve dificuldade na produção de imagens nas áreas de residências devido à restrição de acesso.

\section{Discussão}

Em estudos realizados na cidade do Rio de Janeiro entre 2007 e 2012 observou-se o efeito da média mensal das precipitações sobre o risco de incidência de leptospirose. Foi, então, constatada sazonalidade em relação à incidência da Leptospirose, com concentração maior no verão, período em que há aumento das chuvas (GUIMARÃES ET AL., 2014). Nesse período, a Área de Planejamento 5.2 (região da zona oeste que abrange os bairros de Barra de Guaratiba e Pedra de Guaratiba) atingiu as maiores taxas da doença.

Na epidemia ocorrida em 1996 no município do Rio de Janeiro, verificou-se que a zona oeste obteve os maiores índices de casos da doença, principalmente, em localidade que houve inundações e que continham acumulação de lixo (BARCELLOS; SABROZA, 2001). No município do Rio de Janeiro, as condições de saneamento e dos riscos de inundações foram identificadas como as principais variáveis que determinam os casos de leptospirose. As áreas de favelas e as áreas semirrurais, além das periféricas montanhosas, possuem dificuldades no acesso básico de infraestrutura sanitária - restrições severas para coleta de resíduos, tratamento de esgoto e abastecimento de água (BARCELLOS; SABROZA, 2000).

Um estudo realizado no município do Rio de Janeiro, no período de 1996 a 2009, apontou que áreas sujeitas a inundações são locais que apresentam maiores números de populações com baixa renda, considerado locais com mais casos de leptospirose. Nesse estudo, as Regiões Administrativas (RA) da zona oeste que obtiveram maiores casos incidentes foram: Jacarepaguá, Guaratiba, Bangu, Santa Cruz e Campo Grande. A pluviometria é identificada como extremamente significativa para o surgimento de casos 
de leptospirose, porém não é o único fator determinante para o aumento da incidência da doença: leva-se em consideração também fatores sociais, econômico e de saneamento. Quando há variação pluviométrica concomitantemente com esses outros fatores socioambientais, aumenta-se, de maneira efetiva, o índice de leptospirose no município do Rio de Janeiro, ficando, assim, a população de baixa renda mais vulnerável à variabilidade climática e aos eventos meteorológicos extremos (OLIVEIRA ET AL., 2012).

A transmissão de leptospirose no município do Rio de Janeiro estaria relacionada com a estrutura social e espacial da cidade maior vulnerabilidade da população residindo em áreas desordenadas, com problemas de infraestrutura urbana e áreas sujeitas à inundação (CARRIJO, 2008).

Em um estudo de revisão sistemática sobre fatores associados à leptospirose no Brasil (2000-2009), Pelissari et al. (2011) concluíram que a doença em área urbana estava associada aos baixos níveis socioeconômicos e que em períodos com maior precipitação pluviométricas ocorriam surtos epidêmicos da doença. Outro fator importante que favorece o risco de transmissão da leptospirose são as áreas de favelas urbanas, geralmente são locais com precariedades nas condições ambientais no domicílio e peridomicílio, aliadas às altas infestações de roedores.

Pesquisa realizada em Pernambuco, no período de 2001 a 2009, sugeriu que a leptospirose estaria relacionada com o ambiente domiciliar e com a falta de infraestrutura sanitária. Ressalta-se, ainda, que outros fatores devem ser considerados, como características do terreno (topografia e declividade), tempo de escoamento das enchentes, o período de exposição a essas águas, locais com presença de lixos e a infestação de roedores (VASCONCELOS, 2012).

Períodos que são considerados endêmicos, ou seja, casos esperados de leptospirose, sobretudo em locais de risco, são caracterizados pela ausência de saneamento básico e de coleta de lixo, áreas de favelas e regiões com tendências a constantes inundações. Já em períodos da doença considerados epidêmicos, isto é, taxas de incidência acima do esperado, são marcados por um aumento de casos posteriores a temporais, acometendo também locais com boas condições de saneamento (TASSINARI, 2004).

Quanto à distribuição e a sazonalidade da leptospirose no município de São Paulo, nos anos de 1998 a 2006, foram notificados 773 casos no período seco e 1.717 no úmido. Estudos apontaram que a incidência e a letalidade estavam correlacionadas com as condições socioeconômicas da população, em ambos os períodos (seco ou úmido), sugerindo que a variação dos números de casos de leptospirose não é determinada unicamente pela pluviometria, mas também por múltiplos fatores sociais e ambientais. No município de São Paulo, a leptospirose era contraída, principalmente, pelo contato com água contaminada em épocas chuvosas, havendo características epidemiológicas relacionadas com os fatores socioeconômicos, sugerindo a incidência da doença como um indicador social (SOARES, 2010).

As taxas altas de incidência nos bairros de Pedra de Guaratiba, Barra de Guaratiba e Grumari podem estar relacionadas com as áreas de possíveis alagamentos e baixas condições socioambientais. Essas localidades, apesar de não possuírem áreas de favelas e não serem densamente populosas, são bairros com grandes problemas sociais e que tiveram seu crescimento desordenado e precário em áreas com aspectos ainda agrícolas, e que podem ser vulneráveis à ocorrência da leptospirose. Diferentemente dos bairros localizados na zona norte (AP3) e centro da cidade (AP1), que foram apontados também riscos à ocorrência de leptospirose, são de características bem povoada devido à grande movimentação populacional e ofertas de serviços e comércios, com grande número de favelas e de probabilidades de inundações em períodos de chuvas. 
Verificou-se que, nos resultados, os aspectos da infraestrutura sanitária (oferta de água, serviço de coleta de lixo e de esgoto sanitário) e de renda das áreas com alto risco à leptospirose: Barra de Guaratiba, Pedra de Guaratiba e Grumari. A coleta de lixo, o esgotamento sanitário e abastecimento de água possuem fragilidades nas ofertas dos serviços para a população local nos três bairros. As idas a campo contrapôs alguns dados do Censo 2010: alta oferta de coleta de lixo em Grumari e Pedra de Guaratiba e alta oferta de esgotamento sanitário em Pedra de Guaratiba. O abastecimento de água nessa região (bairros observados) é realizado por meio de poços e nascentes, de acordo com dados do Censo 2010 (IBGE, 2010), o que denota um risco de contaminação da água pela leptospira.

A ocupação inadequada do solo, aliada a falta de estrutura sanitária das habitações, pode criar as condições ambientais propícias para proliferações de roedores, o que intensifica o risco de leptospirose nessas localidades. O agravamento do número intenso de ratos está relacionado com locais com condições de precariedade sanitária, com acesso inadequado de água potável e coleta de lixo insuficiente; a baixa condição socioeconômica contribui, significantemente, para o desenvolvimento de moradias em locais precários (PAPINE, 2012) - e são fatores socioambientais na ocorrência da doença.

O município do Rio de Janeiro possui áreas pobres próximas às áreas de alto poder econômico, ou seja, com desigualdades socioeconômicas, apontando que os estudos sobre vulnerabilidades também devem ser realizados em unidades menores de análise, no intuito de diferenciar as áreas de possíveis riscos dentro do mesmo bairro. Nesse sentido, nas idas a campo nas áreas apontadas com maiores riscos à leptospirose (2000 a 2010) foi possível observar aspectos da realidade local, refletindo e contrapondo com os dados oficiais (macrolocais). Segundo Marandola e Hohan (2009), são necessários foco qualitativo e uma escala menor de análise para compreender melhor a vulnerabilidade, tanto para os aspectos sociocultural e demográficos quanto para a importância do lugar e das comunidades.

A presença de riscos na população de um determinado território que vive em um contexto de vulnerabilidade pode trazer situações, como mortes, doenças e degradação. A complexidade dos riscos é reforçada quando se refletem os contextos vulneráveis nas dimensões sociais. Nesse sentido, é necessário pensar em estratégias integradoras de prevenção e promoção para redução das vulnerabilidades. Como estratégia, as análises de vulnerabilidades podem funcionar a partir da contextualização dos riscos. Assim, amplia-se a prevenção, e a promoção de saúde pode ser discutida e colocada em prática (PORTO, 2012).

\section{Conclusões}

A utilização de Sistema de Informação Geográfica (SIG) como metodológica desta pesquisa trouxe resultados relevantes para subsidiar a análise espacial deste estudo. Retratou de forma abrangente a realidade do município do Rio de Janeiro, ressaltando as áreas com as maiores taxas de incidência por leptospirose, estas que também são áreas com vulnerabilidades socioambientais à ocorrência da doença. A ausência do Estado evidencia a precariedade dos serviços sanitários básicos, como carência do abastecimento de água, falta de coleta regular de lixo e esgotamento sanitário ineficiente.

Os bairros com maiores riscos de ocorrência de leptospirose são locais antrópicos, porém ainda com aspectos agrícolas, onde foram evidenciadas precariedades nas moradias e baixa infraestrutura de saneamento, além de serem áreas que possuem também possibilidades de alagamentos naturais e ocasionados por chuvas, por serem áreas baixas e de mangue. São bairros que tiveram crescimento populacional positivamente nos 
últimos anos, porém ainda possuem baixa densidade demográfica.

Faz-se necessário que as ações de vigilância em saúde e atenção básica levem em consideração as peculiaridades de cada território, assim como reconhecer os problemas daquela população local, a fim de identificar possíveis agravos ou doenças que podem acometer aquelas pessoas e assim intervir de forma mais efetiva. Os contextos geográficos são de grande importância nos processos de adoecimento; nesse sentido, é nos locais com maiores fatores de riscos às doenças e agravos que devem ser focadas as ações de prevenção, promoção e cuidados, como é o caso da incidência à leptospirose.

\section{Colaboradores}

J. V. CHAIBLICH, M. L. S. LIMA e R. F. OLIVEIRA trabalharam nas etapas de planejamento, análise e interpretação e discussão dos dados. M. L. PENNA e M. MONKEN contribuíram na revisão crítica do conteúdo. Todos os autores participaram da aprovação final do manuscrito.

\section{Referências}

\begin{abstract}
ALEIXO, N. C. R.; SANT'ANNA NETO, J. L. Eventos pluviométricos extremos e saúde: perspectivas de interação pelos casos de leptospirose em ambiente urbano. Revista Brasileira de Geografia Médica e da Saúde, Uberlândia, v. 6, n. 11, p. 118-132, dez. 2010. Disponível em: <http://www.seer.ufu.br/index.php/hygeia/article/view/16998>. Acesso em: 5 set. 2016.

BARCELLOS, C.; SABROZA, P. Socio-environmental determinants of the leptospirosis outbreak of 1996 in western Rio de Janeiro: a geographical appoach. International Journal of Environmental Health Research, San Diego, EUA, v. 10, n. 4, p. 301-313, 2000. Disponível em: <https://www.ncbi.nlm.nih.gov/pubmed/11260779>. Acesso em: 5 set. 2016.
\end{abstract}

BARCELLOS, C.; SABROZA, P. The place behind the case: leptopirosis risks and associated environmental conditions en a flood-related outbreak in Rio de Janeiro. Cadernos de Saúde Pública, Rio de Janeiro, v. 17, p. 59-67, 2001. Suplemento. Disponível em: < http:// www.scielo.br/pdf/csp/v17s0/3881.pdf >. Acesso em: 5 set. 2016.

BERGAMASCHI, R. B. SIG Aplicado a segurança no trânsito: estudo de caso no município de Vitória, ES. 74 f. Monografia (Graduação em Geografia) Departamento de Geografia do Centro de Ciências Humanas e Naturais, Universidade Federal do Espírito Santo, Vitória, 2010. Disponível em: <http://www.geo. ufes.br/sites/geografia.ufes.br/files/field/anexo/m bergamasch.pdf>. Acesso em: 5 set. 2016.

BRANDÃO, A. M. P. As alterações climáticas na área metropolitana do Rio de Janeiro: uma provável influência do crescimento urbano. In: ABREU, M. A. (Org.). Natureza e Sociedade no Rio de Janeiro. Rio de Janeiro: Secretaria Municipal de Cultura, 1992. p. 143-200.

BRASIL. Ministério da Saúde. Guia de Vigilância Epidemiológica. 7. ed. Brasília, DF: Ministério da Saúde, 2009. 
Ministério da Saúde. Guia de Vigilância em Saúde. 1. ed. Brasília, DF: Ministério da Saúde, 2014.

CARRIJO, R. O efeito da escala geográfica na análise dos determinantes da leptospirose. 93 f. Dissertação (Mestrado em Saúde Pública) - Escola Nacional de Saúde Pública, Fundação Oswaldo Cruz, Rio de Janeiro, 2008. Disponível em: <http://bvssp.icict.fiocruz.br/pdf/Carrijorsggm.pdf $>$. Acesso em: 5 set. 2016.

GALVÃO, M. C. C. Focos sobre a Questão Ambiental no Rio e Janeiro. In: ABREU, M. A. (Org.). Natureza e Sociedade no Rio de Janeiro. Rio de Janeiro: Secretaria Municipal de Cultura, 1992. p. 13-92.

GONÇALVES, A. J. R. et al. Hemoptises e síndrome de angústia respiratória aguda como causa de morte na leptospirose. Revista Sociedade Brasileira de Medicina

Tropical, Uberaba, v. 25, n. 4, p. 261-70, 1992. Disponível em: $<$ http://www.scielo.br/scielo.php?script=sci abstract\&pid=S0037-86821992000400009\&lng=pt\&nr m=iso\&tlng=pt $>$. Acesso em: 5 set. 2016.

\section{GONÇALVES-DE-ALBUQUERQUE, C. F. et} al. Leptospira and inflammation. Mediators of Inflammation, Cairo, out. 2012.

GUERRA, A. J. T. (Org.). Impactos ambientais urbanos no Brasil. 8. ed. Rio de Janeiro: Bertrand Brasil, 2011.

GUIMARÃES, R. M. et al. Análise temporal da relação entre leptospirose e ocorrência de inundações por chuvas no município do Rio de Janeiro, Brasil, 2007-2012. Ciência \& Saúde Coletiva, Rio de Janeiro, v. 19, n. 9, p. 3683-3692, 2014. Disponível em: <http://www.scielo. br/pdf/csc/v19n9/1413-8123-csc-19-09-3683.pdf>. Acesso em: 5 set. 2016.

\section{INSTITUTO BRASILEIRO DE GEOGRAFIA E} ESTATÍSTICA (IBGE). Censo Demográfico 2010. 2010. Disponível em: <http://www.ibge.gov.br/>. Acesso em: 5 mar. 2015

MARANDOLA, J. R.; HOGAN, D. J. Vulnerabilidade do lugar vs. vulnerabilidade sociodemográfica: implicações metodológicas de uma velha questão. Revista brasileira de Estudo da População, Rio de Janeiro, v. 26, n. 2, p.161-181, 2009. Disponível em: <http://www.scielo. br/pdf/rbepop/v26n2/02.pdf>. Acesso em: 5 set. 2016.

OLIVEIRA T. V. S. et al. Variáveis climáticas, condições de vida e saúde da população: a leptospirose no Município do Rio de Janeiro de 1996 no Município do Rio de Janeiro de 1996 a 2009. Ciência \&t Saúde Coletiva, Rio de Janeiro, v. 17, n. 6, p. 1569-1576, 2012. Disponível em: <http://www.scielo.br/pdf/csc/v17n6/ vl7n6a20.pdf $>$. Acesso em: 5 set. 2016.

PAPINE, S. Vigilância em Saúde Ambiental: uma nova área da ecologia. 2. ed. São Paulo: Atheneu, 2012.

PELISSARI D. M. et al. Revisão sistemática dos fatores associados à leptospirose no Brasil, 2000-2009. Revista Epidemiologia e Serviços de Saúde, Brasília, DF, v. 20, n. 4, p. 565-574, 2011. Disponível em: <http:// scielo.iec.pa.gov.br/scielo.php?script=sci_arttext\&pid $=$ S1679-49742011000400016>. Acesso em: 5 set. 2016.

PORTO, M. F. S. Uma Ecologia Políticas dos Riscos: princípios para integrarmos o local na promoção da saúde e da justiça ambiental. 2. ed. Rio de Janeiro: Fiocruz, 2012.

SANTOS, A. E.; RODRIGUES A. L.; LOPES D. L. Aplicações de Estimadores Bayesianos Empíricos para Análise Espacial de Taxas de Mortalidade. In: SIMPÓSIO BRASILEIRO DE GEOINFORMÁTICA, 8., 2005, Campos do Jordão. Anais... Campo de Jordão: Inpe, 2005. p. 300-309. Disponível em: $<$ http://mtc-ml6c.sid.inpe.br/col/dpi.inpe.br/geoinfo@80/2006/07.11.13.29/doc/P63.pdf>. Acesso em: 5 set. 2016.

SANTOS, B. S.; SANTOS, R. L.; SANTO, S. M. Análise espacial aplicada à expansão de condomínios fechados na Cidade de Feira de Santana (BA). In: SIMPÓSIO BRASILEIRO DE CIÊNCIAS GEODÉSICAS E TECNOLOGIAS DA GEOINFORMAÇÃO, 4., 2012, Recife. Anais... Recife: UFPE, 2012. p. 1-9. Disponível em: <https://www.ufpe.br/cgtg/SIMGEOIV/CD/artigos/SIG/149_5.pdf>. Acesso em: 5 set. 2016.

SOARES, T. S. M. Análise espacial e sazonal da leptospirose no município de São Paulo, SP, 1998 a 2006. 
Cadernos de Saúde Pública, Rio de Janeiro, v. 44, n. 2, p. 283-291, 2010. Disponível em: <http://www.producao. usp.br/bitstream/handle/BDPI/12655/art_SOARES_ Analise_espacial_e_sazonal_da_leptospirose_no_2010. pdf?sequence=1>. Acesso em: 5 set. 2016.

SOUZA, W. V. et. al. Análise Espacial de Dados de Áreas. In: SANTOS, S.M.; SOUZA, W. V. (Org.). Introdução à Estatística Espacial para a Saúde Pública. Brasília: Ministério da Saúde; Rio de Janeiro: Fundação Oswaldo Cruz, 2007. p. 62-78.

TASSINARI, W. S. et al. Distribuição espacial da leptospirose no Município do Rio de Janeiro, Brasil, ao longo dos anos de 1996-1999. Cadernos de Saúde Pública, Rio de Janeiro, v. 20, n. 6, p. 1721-1729, 2004. Disponível em: $<$ http://www.scielo.br/pdf/csp/v20n6/31.pdf >. Acesso em: 5 set. 2016.

VASCONCELOS, C. H. Fatores ambientais e socioeconômicos relacionados à distribuição de casos de leptospirose no Estado de Pernambuco, Brasil, 20012009. Cadernos de Saúde Coletiva, Rio de Janeiro, v. 20, n. 1, p. 49-56, 2012. Disponível em: < http://www.cadernos.iesc.ufrj.br/cadernos/images/csc/2012_1/artigos/ CSC_v20n1_49-56.pdf>. Acesso em: 5 set. 2016.

Recebido para publicação em setembro de 2016

Versão final em dezembro de 2016

Conflito de interesses: inexistente

Suporte financeiro: não houve 